\title{
Development of Wireless Electrical Conductivity Sensor Screening System to Evaluate Protein Binding to Sensor Films
}

\author{
Takaaki Isoda, ${ }^{*}$ Hiroki Ichihara, Koudai Ryujin, Ikuko Urushibara, ${ }^{1}$ and Takao Shimizu ${ }^{1}$ \\ Department of Life and Environment Engineering, Faculty of Environmental Engineering, \\ University of Kitakyushu, 1-1 Hibikino, Wakamatsu, Kitakyushu 808-0135, Japan \\ ${ }^{1}$ AR'S Co., Ltd., 5-1 Yokohama Creation Square, Sakaecho, Yokohama 221-0052, Japan
}

(Received February 26, 2016; accepted September 26, 2016)

Keywords: biosensor, chemical sensor, wireless sensor, electrical conductivity, protein

We developed a wireless electrical conductivity (EC) sensor screening system to evaluate changes in the EC of sensor films. This sensor system was designed to be equipped with a special sensor chip $\left(14 \times 40 \mathrm{~mm}^{2}\right)$, and changes in the EC of a droplet containing a sensor film $(\phi 3 \mathrm{~mm})$ on the chip were determined. Electrode pairs were fabricated on glass substrates by photolithography, and a well structure was formed around each electrode pair using photoreactive resin. This sensor system achieved parallel detection of EC signals from five wells, each containing $5 \mu \mathrm{l}$ of solution with a sensor film in $10 \mathrm{~s}(N=5)$. Furthermore, we developed sensor films that displayed the changes in the EC upon the adsorption and/or chemical binding of protein with $\mathrm{Na}^{+}$as a counterion. To form the sensor films, the surface of cellulose was chemically modified with alkylamino groups. The EC detected the sensor screening system using aminated cellulose with physically adsorbed bovine serum albumin (BSA) and the amount of $\mathrm{Na}^{+}$ions increased linearly with BSA concentration with a correlation coefficient $\left(R^{2}\right)$ of 0.87 . Meanwhile, aminated cellulose with chemically bound BSA through polylysine and glutaraldehyde and adsorbed $\mathrm{Na}^{+}$exhibited an EC that depended on the BSA concentration, with an $R^{2}$ value of 0.943 . The detection limit of BSA was $10 \mathrm{ng} / \mathrm{ml}$ for both types of sensor film. On the basis of our results, the mechanism behind the increased sensitivity of the sensor films with immobilized protein in the presence of a counterion was proposed.

\section{Introduction}

The enzyme-linked immunoassay (ELISA) method has been widely used as a biological assay for medical and/or biological research. ${ }^{(1-3)}$ ELISA uses the principle of antigen-antibody reactions. By the ELISA method, it is possible to determine the concentration of an antigen, such as an enzyme, hormone or activation factor, in a sample solution. An advantage of this assay is that it can detect a specific protein in a mixed sample. Antigen-antibody reactions have also been used to develop many biosensors. A typical biosensor assay using an antigen-antibody reaction involves four steps: (1) preparation of a sample solution containing a protein as the target substance (antigen), (2) preparation of an immobilization solution containing a protein that can react specifically with the antigen (antibody), (3) immobilization of the antibody on a sensor surface, and (4) reaction of the antigen in the sample solution with the antibody on the sensor surface. The resulting chemical

"Corresponding author: e-mail: isoda@kitakyu-u.ac.jp http://dx.doi.org/10.18494/SAM.2017.1365 
and/or physical changes are transformed to an electrical signal that is detected. Improvements in steps 3 and 4 are required for the development of advanced sensors. The challenge regarding step 3 is to develop a technology for fabricating molecular recognition sites that achieve high repeatability. Meanwhile, the challenge facing step 4 is to develop a detection method that realizes high responsivity to a small amount of target substance.

Recently, the quartz crystal microbalance (QCM) and surface plasmon resonance (SPR) methods have been used to analyze the host-guest interactions of molecules on the basis of chemical adsorption. The concentration limits of the target substances using these methods range from ng to $\mathrm{pg}$. As an example of the use of a QCM, polymer-grafted QCM surfaces have been reported to selectively adsorb heavy metal ions such as $\mathrm{Cu}, \mathrm{Pb}, \mathrm{Cr}$, and $\mathrm{Cd} .{ }^{(4)}$ Meanwhile, SPR spectroscopy can be used to measure the nonspecific adsorption of proteins on self-assembled monolayers of alkanethiolates on gold in situ and in real time. ${ }^{(5)}$ An SPR assay using a gold surface modified with a thin polyion complex film to suppress nonspecific protein adsorption has also been developed for immunosensing. ${ }^{(6)}$

The sensitivity of electrode sensors is inferior to those of the SPR and QCM methods. However, the size of the sensor can be decreased by micro-electromechanical system technology. For example, an amperometric method for the determination of the amount of copper ions using disposable, screenprinted electrodes modified with the ligand bis-cyclohexanone oxaldihydrazone has been developed.(7) We previously reported a chip-mounted microelectrode composed of source and drain electrodes coated with an insulator layer and adsorbent particles to immobilize antibody molecules for the detection of antigens in solution. ${ }^{(8,9)}$ The source and drain electrodes were fabricated on a chip; the insulator layer was composed of a novolac resin that was deposited onto $\mathrm{SiO}_{2}$ particles modified with aminoalkyl groups as the adsorbent on the electrodes. Antibody molecules were quickly immobilized onto the aminated $\mathrm{SiO}_{2}$ particles by means of various adsorption phenomena. An electric double layer forms at its surface when a liquid is deposited on an insulator. In the electric double layer, the insulator molecules become polarized, resulting in opposing charges at the interface between the liquid and the solid, as well as on the opposite side of the insulator. In the case of a solution containing antigen molecules that capture the surface of an insulator with immobilized antibodies, specific antigen-antibody reactions occur, causing the charge at the opposite side of the insulator to increase. On the basis of the principle, a source-drain electrode produces a signal in response to changes in the current induced by the antigen-antibody reactions at the surface of the insulator layer.

However, this measurement approach is limited by its poor repeatability. The sensitivity of an antigen-antibody reaction depends on the amount of antibodies adsorbed onto the surface of the aminated $\mathrm{SiO}_{2}$ particles, even though the dispersion and amount of aminated $\mathrm{SiO}_{2}$ particles could not be controlled on the source-drain electrodes. Therefore, an electrode chip surface that can be modified uniformly and quickly achieves maximum adsorption of the host molecule must be created as an alternative to the aminated $\mathrm{SiO}_{2}$ particles.

In this study, we developed a wireless-type electrical conductivity (EC) sensor screening system to evaluate changes in the EC of sensor materials. This sensor system was designed to be equipped on a special sensor chip and allow changes in the EC of a droplet on the chip to be determined. A pair of electrodes on the glass substrate is fabricated by photolithography, and a well structure around the electrode pair is formed using photoreactive resin. We also developed sensor films that change their electric charge depending on the adsorption and/or chemical binding of protein. The surface of the cellulose films is chemically modified with alkylamino groups, and 
bovine serum albumin (BSA) is used as the protein. The EC of various sensor films is evaluated using the developed EC sensor screening system. The detection mechanism of the adsorbed and/or chemically bound protein molecules on the aminated cellulose films is discussed in reference to our results.

\section{Materials and Methods}

\subsection{Detection principle of adsorbed or chemically bonded protein on a sensor film}

Figure 1 shows the structure of a sensor electrode and the detection mechanism using a sensor film. A cross section of a sensor electrode is shown in Fig. 1(a). A pair of electrodes is mounted on a glass substrate and a well structure around the electrode pair is formed using photoreactive resin. This detection site is referred to simply as a well. Electrode pairs are connected to an external amplifier circuit. A sensor film is put in a well and distilled water (DW) is added. A droplet is formed as a result of the lipophilic ability of the well. The EC of the droplet containing a sensor film can be detected by the external amplifier circuit.

A schematic illustration of the surface structure of a sensor film is presented in Fig. 1(b). The sensor was composed of a cellulose film having a surface modified with amino groups (aminated cellulose). The surface was further immobilized by physical adsorption and/or chemical binding of protein. Therefore, the surface of the aminated cellulose film exhibits a negative charge because proteins are polarized in DW and possess a negative charge [Fig. 1(b); Cases 1 and 2]. Furthermore, it is widely known that an ion layer, such an electric double layer, forms at the interface between a solid and a liquid. ${ }^{(10)}$ Cations such as $\mathrm{Na}^{+}$can bind to a protein molecule supported on the sensor

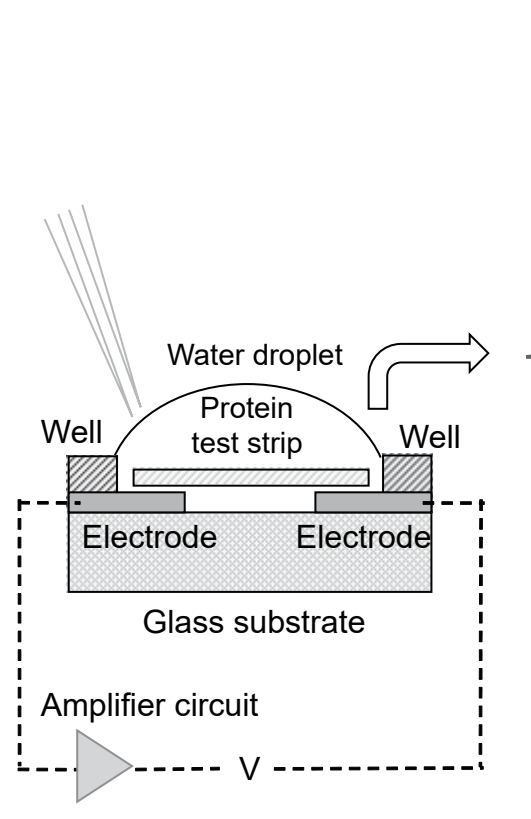

(a)

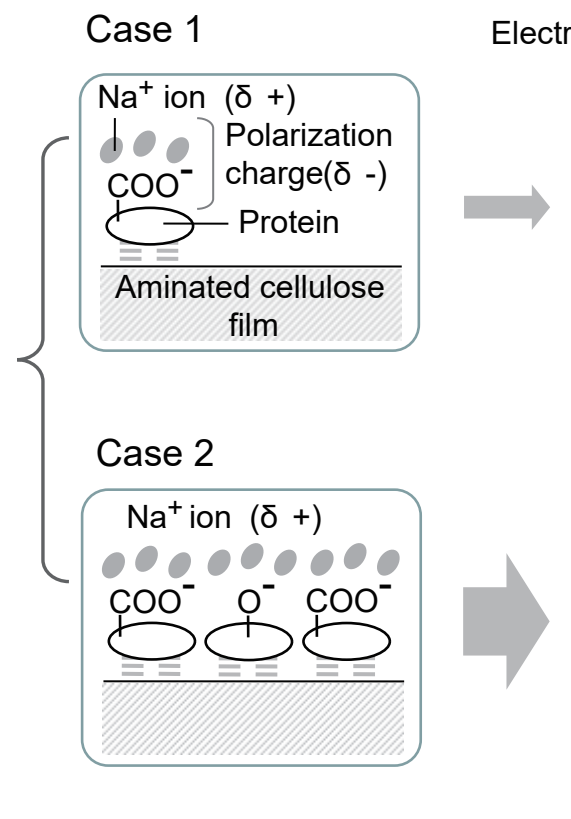

(b)
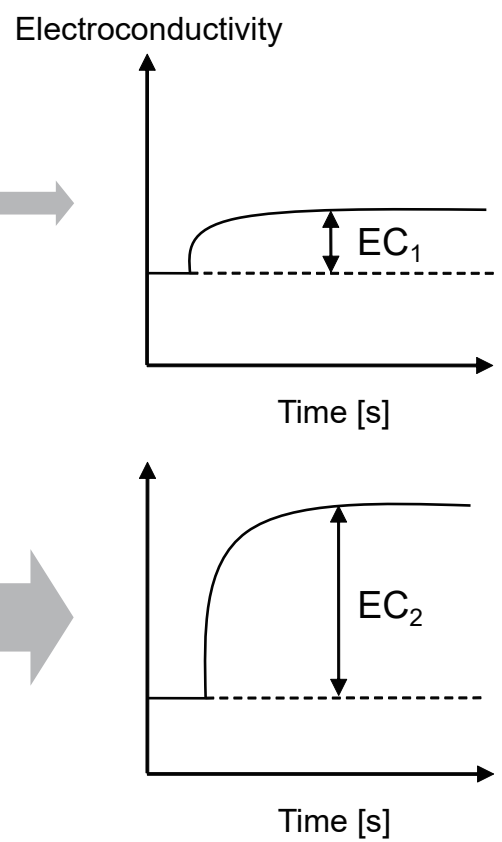

(c)

Fig. 1. (a) and (b) Structure of a sensor electrode, and (c) detection mechanism using a sensor film. 
film surface through electrical interaction. Therefore, the positive charge on the sensor film is small when a small amount of protein is immobilized on its surface [Fig. 1(b); Case 1]. In contrast, the positive charge on the film will be greater as the protein content on the surface increases [Fig. 1(b); Case 2]. The charge of the sensor is detected by an electrode in the well.

Figure 1(c) shows the detection mechanism of EC. EC is the degree of current flow in a solution and is defined as ${ }^{(11)}$

$$
K=L / S R
$$

Here, $K$ is EC [S m$\left.{ }^{-1}\right], L$ is the distance between two electrodes (m), $S$ is the dimensions of the electrode $\left(\mathrm{m}^{2}\right)$, and $R$ is the resistance $(\Omega)$. In accordance with Eq. (1), EC increases with decreasing $R$ of a solution. The $R$ of a solution depends on the concentration of ions and/or mobility of electrons. Therefore, the sensor response will be small when the content of the immobilized protein is small [Fig. 1(b); Case 1] and will be large when the content of the immobilized protein is large [Fig. 1(b); Case 2].

\subsection{Surface modification of cellulose with amino groups}

Figure 2 outlines amino-silane coupling on the surface of cellulose. A 2\% aqueous solution of 3-aminopropyltrimethoxysilane (KM-903, Shinetsu Chemical Co., Ltd., Japan) was used as the silane coupling reagent [Fig. 2(a)]. The substrate was hydrolyzed at room temperature for $0.5 \mathrm{~h}$ with stirring to obtain aminosilanol [Fig. 2(b)]. A cellulose film with the dimensions of $20 \times 35$ $\mathrm{mm}^{2}$ was dipped in the aminosilanol solution for $20 \mathrm{~min}$, allowing aminosilanol to be chemically adsorbed to hydroxyl groups on the cellulose surface [Fig. 2(c)]. The silane coupling reaction was then carried out at $100{ }^{\circ} \mathrm{C}$ to yield aminated cellulose [Fig. 2(d)]. After drying under vacuum, the cellulose film was cut into circles with a diameter $\phi$ of $3 \mathrm{~mm}$ and used for sensor evaluation.<smiles>CO[Si](OC)(OC)ON</smiles>

(a)

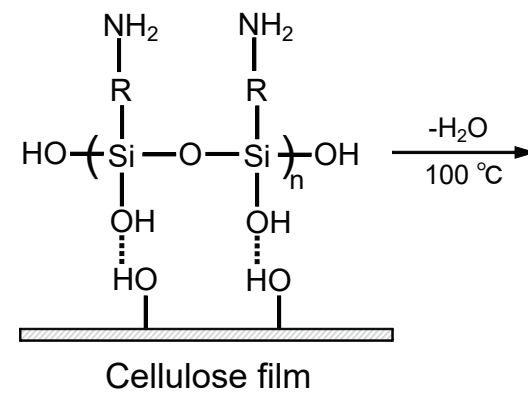

(c)

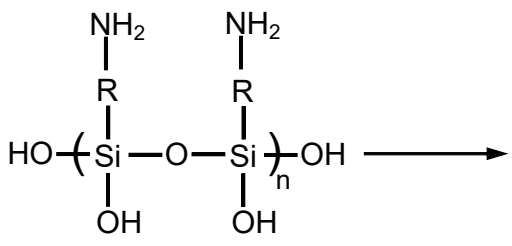

(b)

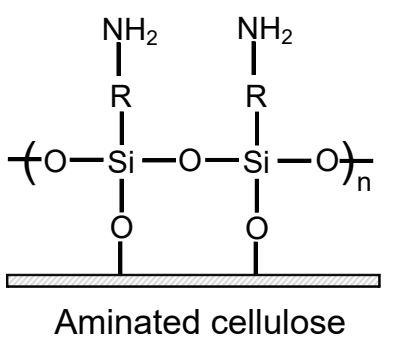

(d)

Fig. 2. Amino-silane coupling on the surface of cellulose. 
Figure 3 illustrates a fluorescent labeling reaction on the surface of aminated cellulose. Fluorescent labeling was carried out using fluorescein isothiocyanate (FITC, Dojindo Laboratories Co., Ltd., Japan) to examine the degree of amination of the cellulose surface. The chemical structure of FITC is shown in Fig. 3(a). The isothiocyanate group $(-\mathrm{N}=\mathrm{C}=\mathrm{S})$ of FITC reacts with a primary amine on the cellulose surface to form a thiourea bond [Fig. 3(b)]. Therefore, it is possible to fluorescently label amino groups selectively using FITC. The connected FITC exhibits green fluorescence following excitation at $520 \mathrm{~nm}$. Fluorescence images were taken with a fluorescence microscope (U-RFLT50, Olympus Co., Ltd., Japan), and the degree of amination of the cellulose surface was determined from the intensity of these images.

\subsection{Protein immobilization on aminated cellulose by adsorption}

Figure 4 shows the immobilization of a protein on aminated cellulose by adsorption. Protein immobilization solutions composed of different concentrations of BSA dissolved in phosphatebuffered saline (PBS) were prepared. Aminated cellulose was added to each solution at $37^{\circ} \mathrm{C}$ for 1 $\mathrm{h}$ to allow BSA to physically adsorb on the aminated surface [Fig. 4(1)]. The BSA-adsorbed sensor film was washed in DW for 5 min and then its EC was evaluated using an EC sensor system. The sensor film was added to an aqueous solution of $\mathrm{NaCl}(10 \mathrm{mmol} / \mathrm{l})$ for $5 \mathrm{~min}$, causing $\mathrm{Na}^{+}$to adsorb on BSA as a counterion [Fig. 4(2)]. The BSA-adsorbed sensor film with $\mathrm{Na}^{+}$ions was washed in DW for 5 min and then its EC was also evaluated.

\subsection{Protein immobilization on aminated cellulose by chemical bonding}

Figure 5 illustrates protein immobilization on aminated cellulose by chemical bonding. Aminated cellulose was added to a $50 \mathrm{wt} \%$ aqueous solution of glutaraldehyde (GA, Wako Pure Chemical Industries Co., Ltd., Japan) at room temperature for $5 \mathrm{~min}$, causing GA to chemically bind to the amino groups [Fig. 5(1)]. The film was washed in DW for $5 \mathrm{~min}$ and then added to a solution of polylysine (PL, Tokyo Kasei Industries Co., Ltd., Japan) in PBS (100 $\mu \mathrm{g} / \mathrm{ml})$ at room temperature for $5 \mathrm{~min}$ [Fig. 5(2)]. Then, more GA was linked to PL by the same procedure as in Fig. 5(1) [Fig. 5(3)]. After washing the sensor film in DW for $5 \mathrm{~min}$, it was added to a solution of

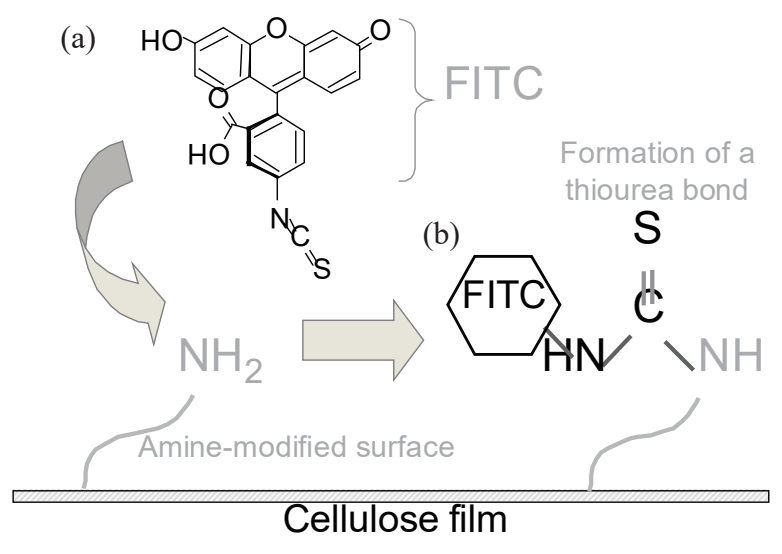

Fig. 3. Fluorescent labeling reaction on the surface of aminated cellulose. 


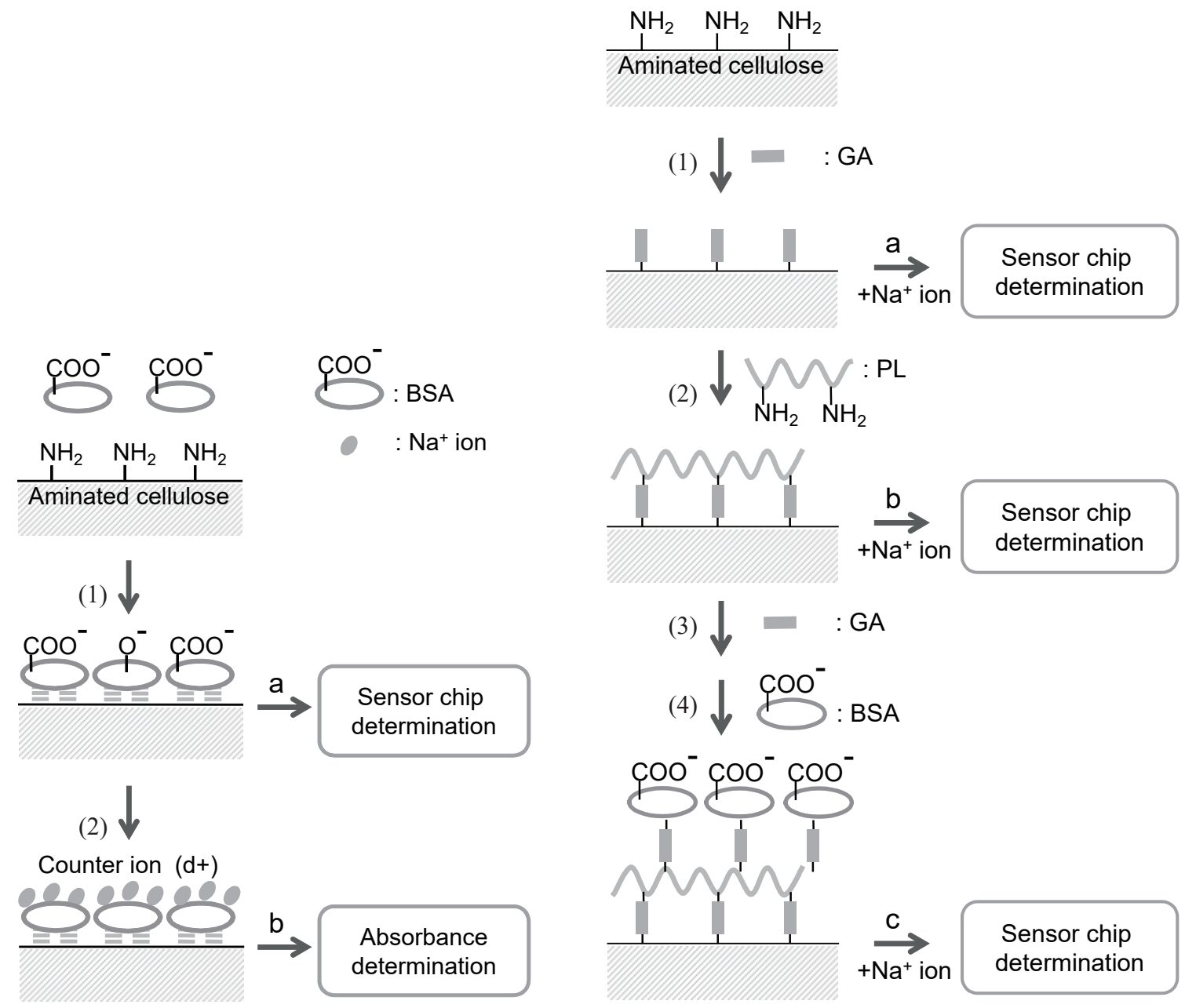

Fig. 4. Immobilization of a protein on aminated cellulose by adsorption.

Fig. 5. Immobilization of a protein on aminated cellulose by chemical bonding. BSA is bovine serum albumin, GA is glutaraldehyde, and PL is polylysine.

BSA in PBS of a given concentration at room temperature for 5 min [Fig. 5(4)]. After washing the sensor film in DW for $5 \mathrm{~min}$, aminated cellulose with chemically bound BSA was obtained. The BSA-immobilized films were then added to an aqueous solution of $\mathrm{NaCl}(10 \mathrm{mmol} / \mathrm{l})$ for $5 \mathrm{~min}$, allowing $\mathrm{Na}^{+}$to be adsorbed on BSA as a counterion. The BSA-immobilized sensor film with $\mathrm{Na}^{+}$ ions was washed in DW for 5 min and its EC was evaluated.

\subsection{Fabrication of sensor array chip}

Figure 6 shows the fabrication steps of a sensor array chip. A Cr adhesion layer $(0.1 \mu \mathrm{m}$ thick) was sputtered on a glass wafer. A positive-type photoresist layer was spin-coated on the $\mathrm{Cr}$ surface and then patterned by irradiation with UV light through a Cr-coated soda-lime glass mask [Fig. 6(a)]. After irradiation, the exposed regions of the resist layer were removed using a 25 $\mathrm{wt} \%$ tetramethylammonium hydroxide solution [Fig. 6(b)]. The Cr layer was etched using a ceric ammonium nitrate solution (5 wt\%) [Fig. 6(b)]. The remaining photoresist layer was removed 


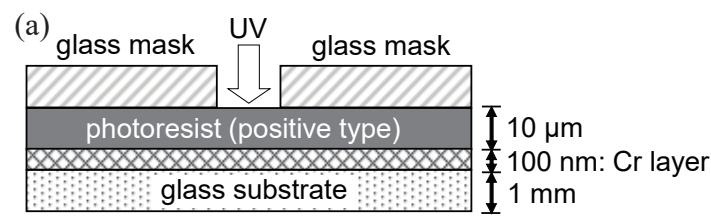

(b)
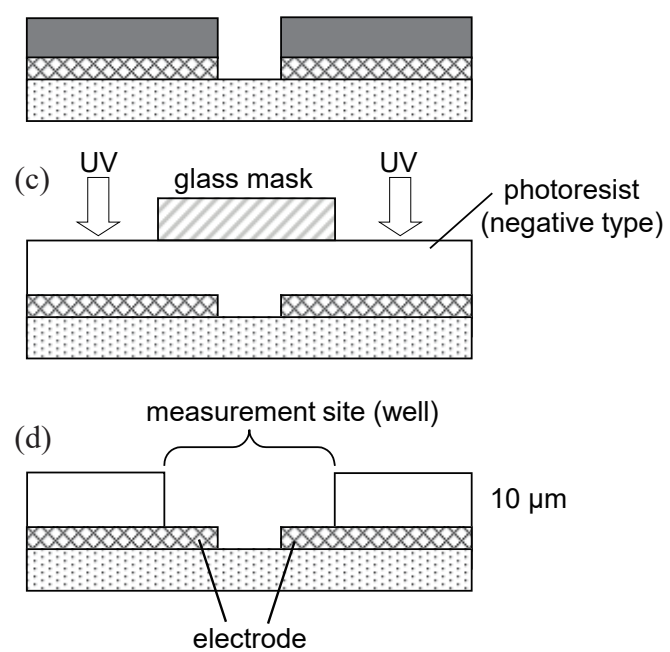

Fig. 6. Fabrication of a sensor array chip.

by washing extensively in acetone. A negative-type photoresist layer (SU-8, Micro Chem., USA) was spin-coated on the $\mathrm{Cr}$ surface and then patterned by irradiation with UV light through a Crcoated soda-lime glass mask [Fig. 6(c)]. After irradiation, the unexposed regions of the resist were removed using a developer (SU8-developer, Micro Chem.) [Fig. 6(d)], giving an electrode chip with a well structure. A photograph of an electrode chip is shown in Fig. 7. Ten pairs of electrodes in each well $(\phi 2.93 \mathrm{~mm})$ were arranged on a chip with an area of $16 \times 42 \mathrm{~mm}^{2}$. The electrodes were connected to an amplification circuit in the EC sensor screening system through pads arranged at the edges of the chip.

\subsection{Fabrication of wireless EC sensor screening system}

Figure 8(a) shows a photograph of the developed wireless EC sensor screening system for detecting signals from the electrode chip. A diagram outlining signal conversion is shown in Fig. 8(b). The electrode chip [1 in Fig. 8(a)] is attached to a transmitter (overall size: $24.5 \times 20 \times 90.5$ $\mathrm{mm}^{3}$, weight: $70 \mathrm{~g}$ ) [2 in Fig. 8(a)]. When a solution containing the cellulose-based sensor films is added to the well, the converted digital signals from the electrodes are transmitted to a receiver $[3$ in Fig. 8(a)] located $5 \mathrm{~m}$ from the point of detection.

The performance of the wireless EC sensor system is summarized in Table 1. The wireless system developed using the package module 'Miniship ${ }^{\mathrm{TM}}$ ' contained both a transmitter and a receiver. This device (dimensions of $25 \times 25 \times 10 \mathrm{~mm}^{3}$ and weight of $70 \mathrm{~g}$ ) includes a PIC CPU. The power needed to drive this device $(3.7 \mathrm{~V})$ was supplied by a NiMH rechargeable battery fitted within the transmitter and/or attached via USB to a smart phone and/or PC. The electrodes mounted on the electrode chip were connected to an A/D converter with an amplifier circuit. Each 


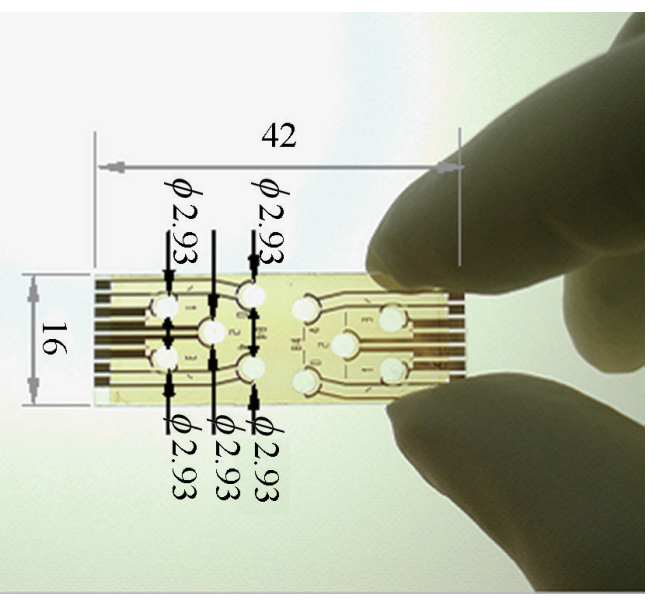

Fig. 7. (Color online) Photograph of a sensor array chip. Values are in $\mathrm{mm}$.

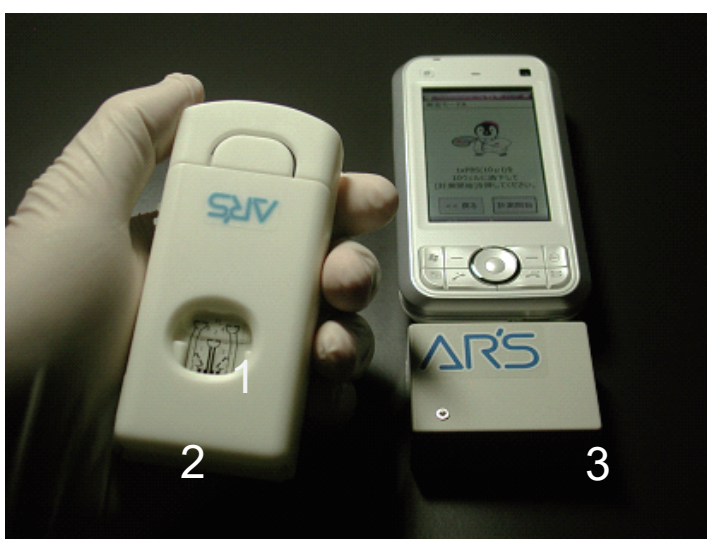

(a)

\section{2) Transmitter}

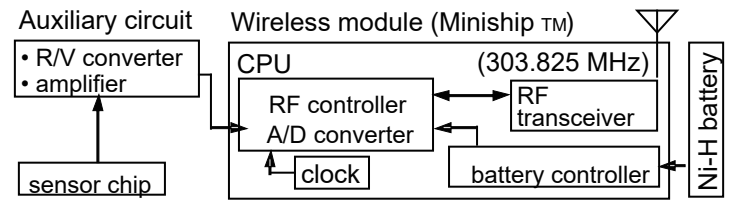

*3) Receiver

\begin{tabular}{|c|c|c|c|}
\hline$\nabla_{\mathrm{PC}}$ & onnection board & \multirow{3}{*}{$\begin{array}{c}\text { USB } \\
\text { connection } \\
\text { bus power }\end{array}$} & \multirow{3}{*}{$\begin{array}{l}\text { Smart phone } \\
\begin{array}{|l}\text { data } \\
\text { - display } \\
\text { - save } \\
\text { - processing }\end{array}\end{array}$} \\
\hline $\begin{array}{l}\text { wireless } \\
\text { module }\end{array}$ & $\Rightarrow \begin{array}{c}\text { serial/USB } \\
\text { converter }\end{array}$ & & \\
\hline (MinishipTM) & battery controller & & \\
\hline
\end{tabular}

(b)

Fig. 8. (Color online) (a) Photograph of a wireless sensor system and (b) a diagram of signal conversion. 1 is the sensor array chip, 2 is the transmitter module, and 3 is the receiver module.

Table 1

Performance of a wireless EC sensor system.

\begin{tabular}{|c|c|c|c|}
\hline Device & Item & \multicolumn{2}{|c|}{ Information } \\
\hline \multirow{7}{*}{ Transmitter } & $\mathrm{CPU}$ & PIC18LF452 & (Microchip) \\
\hline & \multirow{3}{*}{ RF } & Frequency & $303.825 \mathrm{MHz}$ \\
\hline & & Modulation system & ASK \\
\hline & & Transfer speed & $19.2 \mathrm{kbps}$ \\
\hline & Circuit for sensor I/F & \multicolumn{2}{|c|}{$\mathrm{R} / \mathrm{V}$ converter circuit + amplifier circuit } \\
\hline & Power supply & Charging battery & $3.7 \mathrm{~V}$ \\
\hline & Overall size & \multicolumn{2}{|c|}{$24.5 \times 90.5 \mathrm{~mm}^{2}$} \\
\hline Device & Item & \multicolumn{2}{|c|}{ Information } \\
\hline \multirow{7}{*}{ Transmitter } & $\mathrm{CPU}$ & PIC18LF452 & (Microchip) \\
\hline & \multirow{3}{*}{$\mathrm{RF}$} & Frequency & $303.825 \mathrm{MHz}$ \\
\hline & & Modulation system & ASK \\
\hline & & Transfer speed & $19.2 \mathrm{kbps}$ \\
\hline & $\mathrm{PC} \mathrm{I} / \mathrm{F}$ & \multicolumn{2}{|c|}{ USB (virtual serial) } \\
\hline & Power supply & supply to USB & $5 \mathrm{~V}$ \\
\hline & Overall size & \multicolumn{2}{|c|}{$24.5 \times 40.5 \mathrm{~mm}^{2}$} \\
\hline
\end{tabular}


sensor signal was A/D converted by a CPU driven by a battery control unit and a clock generator unit. The digital signal was transmitted by a RF transceiver [2 in Fig. 8(b)]. A transmitted signal of $303.825 \mathrm{MHz}$ was received by this device and converted into a current signal by a serial/USB converter [3 in Fig. 8(b)]. The current signal sent to a smartphone and/or PC was then analyzed using appropriate software.

\subsection{Evaluation of immobilized protein film using sensor array chip}

The performance of the cellulose-based sensor films was evaluated as follows:

(1) A sensor electrode chip was set up on a wireless EC screening system and a cellulose-based sensor film was placed in each of the five wells that were filled with DW $(5 \mu l)$.

(2) PC software for the wireless EC screening system was started and the electrode voltage of the five wells was measured at $500 \mathrm{~ms}$ intervals for $10 \mathrm{~s}$.

(3) Average voltages obtained from each well over the $10 \mathrm{~s}$ in the measurement film were calculated, and the detection voltage, as defined by Eq. (2), was obtained.

$$
E_{X}=\left(E_{1}+E_{2}+E_{3}\right) / 3
$$

Here, $E_{X}$ is the average sensor voltage detected using three wells $\left(E_{1}\right.$ to $\left.E_{3}\right)$. The voltages obtained from the two wells that exhibited the minimum and maximum detection voltages were excluded from the calculation.

(4) The relative sensor voltage $R_{E}$, as defined by Eq. (3), was also calculated.

$$
R_{E}=E_{X} / E_{0}
$$

Here, $E_{0}$ is the average sensor voltage when using a control sensor film with an aminated surface and adsorbed $\mathrm{Na}^{+}$ions.

\section{Results}

\subsection{Surface modification of cellulose films with alkylamino groups}

Changes in the fluorescence of cellulose films before and after alkylaminosilane coupling reaction are summarized in Table 2. An unmodified cellulose film (sample 1), a cellulose film with adsorbed FITC (sample 2), and an aminated cellulose (sample 3) exhibited fluorescence intensities

Table 2

Changes in the fluorescent labeling of sheetlike cellulose before and after alkylaminosilane coupling.

\begin{tabular}{lcccc}
\hline Sample & Material & $\begin{array}{c}\text { Treatment in FITC } \\
\text { aqueous solution }^{1)}\end{array}$ & $\begin{array}{c}\text { Average fluorescence } \\
\text { intensity }(-)\end{array}$ & Standard deviation \\
\hline 1 & \multirow{2}{*}{ Cellulose } & None & 20 & 3 \\
2 & 5 min & 60 & 10 \\
\hline 3 & \multirow{2}{*}{ Aminated cellulose } & None & 55 & 5 \\
4 & 5 min & 248 & 2 \\
\hline
\end{tabular}


of $20 \pm 3,60 \pm 10$, and $55 \pm 5$, respectively. In contrast, the fluorescence intensity of aminated cellulose labeled with FITC (sample 4) was markedly higher at $248 \pm 2$. This indicates that FITC was chemically bound to the cellulose surface modified with alkylamino groups, as shown in Fig. 3.

\subsection{Relationship between detection voltage of electrode and number of sensor films in a well}

Figure 9 shows the relationships between the relative voltage and the number of sensor films added to a well. Experimental conditions and the results of sensor evaluation are summarized in Table 3. In Fig. 9 and Table 3, Nos. 1, 4, and 7 show the detected sensor voltage when DW (5 $\mu$ ) was added to a well as a control. This value corresponds to $E_{0}$ in Eq. (3) and the relative voltage $R_{E}$ equals 1. $R_{E}$ increased to 3.57 when an unmodified cellulose film was added (No. 2), and increased slightly further to 3.71 when two cellulose films were added (No. 3). A similar trend was found for aminated cellulose film, with $R_{E}$ of 2.06 for one film (No. 5) and 2.38 for two films (No. 6). Thus, detection voltage markedly increased upon the addition of one sensor film in a droplet of DW, but did not increase much further when two sensor films were added to the droplet. $R_{E}$ did not change when a Teflon (PTFE) film in DW was measured, giving $R_{E}$ of 1.66 for one film (No. 8) and 1.65 for two (No. 9).

\subsection{Evaluation of detection voltage using aminated cellulose film with adsorbed protein}

Figure 10 shows the relative voltage obtained for sensor evaluation using an aminated cellulose film with adsorbed $\mathrm{Na}^{+}$ions as a control (No. $\left.{ }^{*} 10\right)$, aminated cellulose film with adsorbed BSA (No. $\left.{ }^{*} 11\right)$, and aminated cellulose film with adsorbed BSA and $\mathrm{Na}^{+}$ions (No. $\left.{ }^{*} 12\right)$. Experimental conditions and the results of sensor evaluation are summarized in Table 4. No. 10 is a control, and its detected voltage corresponds to $E_{0}$ in Eq. (3) with $R_{E}$ equal to 1 . No. 11 (aminated cellulose film with adsorbed BSA) had $R_{E}$ of 1.13. Meanwhile, No. 12 (aminated cellulose film with adsorbed BSA and $\mathrm{Na}^{+}$ions) displayed $R_{E}$ of 1.35 .

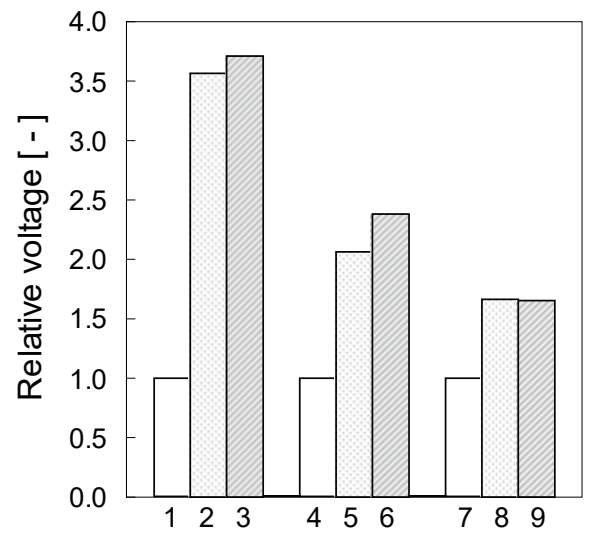

Table 3

Experimental conditions and the results of sensor evaluation (part 1).

\begin{tabular}{ccccc}
\hline No. & Sample & $\begin{array}{c}\text { Number of } \\
\text { sheets }\end{array}$ & $\begin{array}{c}\text { Average sensor } \\
\text { voltage }[\mathrm{mV}]\end{array}$ & $\begin{array}{c}\text { Relative } \\
\text { voltage }\end{array}$ \\
\hline 1 & DW & (control) & 289 & 1.00 \\
2 & DW + cellulose & 1 & 1029 & 3.57 \\
3 & & 2 & 1070 & 3.71 \\
\hline 4 & DW & (control) & 462 & 1.00 \\
5 & DW + aminated & 1 & 953 & 2.06 \\
6 & cellulose & 2 & 1101 & 2.38 \\
\hline 7 & DW & $($ control) & 438 & 1.00 \\
8 & DW + Teflon & 1 & 729 & 1.66 \\
9 & & 2 & 725 & 1.65 \\
\hline
\end{tabular}

Fig. 9. Relationship between the relative voltage obtained from sensor evaluation and number of sensor films in a well. 


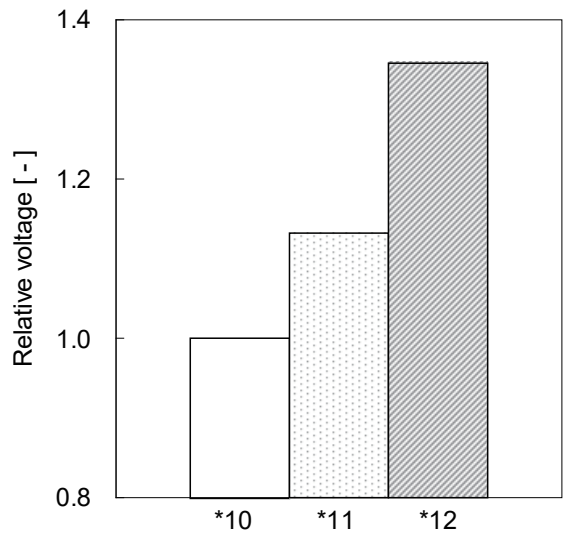

Fig. 10. Relative voltage obtained from sensor evaluation of *10) aminated cellulose with adsorbed $\mathrm{Na}^{+}$ions (control), *11) aminated cellulose with adsorbed BSA, and *12) aminated cellulose with adsorbed BSA, and $\mathrm{Na}^{+}$ ions. Preparation procedures are summarized in Table 4.

Table 4

Experimental conditions and the results of sensor evaluation (part 2).

\begin{tabular}{|c|c|c|c|c|c|}
\hline \multirow[b]{2}{*}{ No. } & \multicolumn{3}{|c|}{ Sample } & \multirow{2}{*}{$\begin{array}{c}\text { Average } \\
\text { sensor } \\
\text { voltage }(\mathrm{mV})\end{array}$} & \multirow{2}{*}{$\begin{array}{c}\text { Relative } \\
\text { voltage }\end{array}$} \\
\hline & $\begin{array}{c}\text { Surface modification of } \\
\text { aminated voltage cellulose }\end{array}$ & Preparation procedure & Concentration of substrate & & \\
\hline$* 10$ & $\mathrm{NaCl}$ aqueous solution (control) & Adsorption $5 \mathrm{~min}$ & $0.01 \mathrm{~mol} / \mathrm{L}$ & 852 & 1.00 \\
\hline$* 11$ & BSA aqueous solution & Adsorption $37^{\circ} \mathrm{C}$ for $1 \mathrm{~h}$ & $100 \mu \mathrm{g} / \mathrm{mL}$ & 965 & 1.13 \\
\hline *12 & $\begin{array}{l}\text { 1st: } \mathrm{BSA} \text { aqueous solution, } \\
\text { 2nd: } \mathrm{NaCl} \text { aqueous solution }\end{array}$ & $\begin{array}{c}\text { Adsorption } \\
1 \text { st: } 37^{\circ} \mathrm{C} \text { for } 1 \mathrm{~h} 2 \mathrm{nd}: 5 \mathrm{~min}\end{array}$ & $\begin{array}{l}\text { 1st: } 100 \mu \mathrm{g} / \mathrm{mL} \\
\text { 2nd: } 0.01 \mathrm{~mol} / \mathrm{L}\end{array}$ & 1146 & 1.35 \\
\hline$* 13$ & $\mathrm{NaCl}$ aqueous solution (control) & Adsorption $5 \mathrm{~min}$ & $0.01 \mathrm{~mol} / \mathrm{L}$ & 1064 & 1.00 \\
\hline$* 14$ & $\begin{array}{l}\text { 1st: } \mathrm{BSA} \text { aqueous solution } \\
\text { 2nd: } \mathrm{NaCl} \text { aqueous solution }\end{array}$ & $\begin{array}{c}\text { Adsorption } \\
1 \text { st: } 37^{\circ} \mathrm{C} \text { for } 1 \mathrm{~h} 2 \mathrm{nd}: 5 \mathrm{~min}\end{array}$ & $\begin{array}{l}\text { 1st: } 0.01 \mu \mathrm{g} / \mathrm{mL} \\
\text { 2nd: } 0.01 \mathrm{~mol} / \mathrm{L}\end{array}$ & 1111 & 1.04 \\
\hline$* 15$ & same as 14 above & same as 14 above & 1st: $0.1 \mu \mathrm{g} / \mathrm{mL}, 2 \mathrm{nd}: 0.01 \mathrm{~mol} / \mathrm{L}$ & 1123 & 1.06 \\
\hline$* 16$ & same as 14 above & same as 14 above & 1st: $1 \mu \mathrm{g} / \mathrm{mL}, 2 \mathrm{nd}: 0.01 \mathrm{~mol} / \mathrm{L}$ & 1127 & 1.06 \\
\hline$* 17$ & same as 14 above & same as 14 above & 1st: $10 \mu \mathrm{g} / \mathrm{mL}, 2 \mathrm{nd}: 0.01 \mathrm{~mol} / \mathrm{L}$ & 1155 & 1.08 \\
\hline$* 18$ & $\mathrm{NaCl}$ aqueous solution (control) & Adsorption $5 \mathrm{~min}$ & $0.01 \mathrm{~mol} / \mathrm{L}$ & 975 & 1.00 \\
\hline *19 & $\begin{array}{l}\text { 1st: } \mathrm{GA} \text { aqueous solution } \\
\text { 2nd: } \mathrm{NaCl} \text { aqueous solution }\end{array}$ & $\begin{array}{l}\text { 1st (Reaction): } 5 \mathrm{~min} \\
\text { 2nd (Adsorption): } 5 \mathrm{~min}\end{array}$ & $\begin{array}{c}\text { 1st: } 50 \% \\
\text { 2nd: } 0.01 \mathrm{~mol} / \mathrm{L}\end{array}$ & 782 & 0.80 \\
\hline *20 & $\begin{array}{l}\text { 1st: GA aqueous solution } \\
\text { 2nd: } \mathrm{PL} / \mathrm{PBS} \text { solution } \\
\text { 3rd: } \mathrm{NaCl} \text { aqueous solution }\end{array}$ & $\begin{array}{l}\text { 1st and 2nd (Reaction): } \\
\text { each } 5 \text { min, } \\
\text { 3rd (Adsorption): } 5 \text { min }\end{array}$ & $\begin{array}{c}\text { 1st: } 50 \% \\
\text { 2nd: } 100 \mu \mathrm{g} / \mathrm{mL} \\
\text { 3rd: } 0.01 \mathrm{~mol} / \mathrm{L} \\
\end{array}$ & 814 & 0.83 \\
\hline$* 21$ & $\begin{array}{l}\text { 1st: GA aqueous solution } \\
\text { 2nd: PL/PBS solution } \\
\text { 3rd: GA aqueous solution } \\
\text { 4th: } \mathrm{BSA} \text { aqueous solution } \\
\text { 5th: } \mathrm{NaCl} \text { aqueous solution }\end{array}$ & $\begin{array}{l}\text { 1st to 4th (Reaction) : } \\
\text { each } 5 \text { min } \\
\text { 5th (Adsorption): } 5 \text { min }\end{array}$ & $\begin{array}{c}\text { 1st and 3rd: each } 50 \% \text {, } \\
\text { 2nd and 4th: each } 100 \mu \mathrm{g} / \mathrm{mL} \text {, } \\
\text { 5th: } 0.01 \mathrm{~mol} / \mathrm{L}\end{array}$ & 904 & 0.93 \\
\hline$* 22$ & $\mathrm{NaCl}$ aqueous solution (control) & Adsorption $5 \mathrm{~min}$ & $0.01 \mathrm{~mol} / \mathrm{L}$ & 937 & 1.00 \\
\hline$* 23$ & $\begin{array}{l}\text { 1st: GA aqueous solution } \\
\text { 2nd: PL/PBS solution } \\
\text { 3rd: GA aqueous solution } \\
\text { 4th: } \mathrm{BSA} \text { aqueous solution } \\
\text { 5th: } \mathrm{NaCl} \text { aqueous solution }\end{array}$ & $\begin{array}{l}\text { 1st to 4th (Reaction): } \\
\text { each } 5 \text { min, } \\
\text { 5th (Adsorption): } 5 \text { min }\end{array}$ & $\begin{array}{l}\text { 1st and 3rd: each 50\%, } \\
\text { 2nd: } 100 \mu \mathrm{g} / \mathrm{mL}, \\
\text { 4th: } 0.01 \mu \mathrm{g} / \mathrm{mL}, \\
\text { 5th: } 0.01 \mathrm{~mol} / \mathrm{L}\end{array}$ & 886 & 0.95 \\
\hline$* 24$ & same as 23 above & same as 23 above & $\begin{array}{l}\text { 1st to 3rd and 5th: same as } \\
\text { above, } 4 \text { th: } 0.1 \mu \mathrm{g} / \mathrm{mL}\end{array}$ & 899 & 0.96 \\
\hline *25 & same as 23 above & same as 23 above & $\begin{array}{l}\text { 1st to 3rd and 5th: same as } \\
\text { above, } 4 \text { th: } 1 \mu \mathrm{g} / \mathrm{mL}\end{array}$ & 926 & 0.99 \\
\hline *26 & same as 23 above & same as 23 above & $\begin{array}{l}\text { 1st to 3rd and 5th: same as } \\
\text { above, } 4 \text { th: } 10 \mu \mathrm{g} / \mathrm{mL}\end{array}$ & 968 & 1.03 \\
\hline
\end{tabular}


Figure 11 shows the relationship between the relative voltage of the aminated cellulose film with adsorbed BSA and $\mathrm{Na}^{+}$ions and the concentration of BSA. Preparation details of samples No. $* 14$ to $* 17$ in Fig. 11 are summarized in Table 4. No. 13 is a control comprising an aminated cellulose film with $\mathrm{Na}^{+}$ions and has $R_{E}$ of 1 . Nos. 14 to 17 are aminated cellulose films with different concentrations of adsorbed BSA and $\mathrm{Na}^{+}$ions. For these samples, $R_{E}$ increased with the concentration of BSA, with $R_{E}$ of 1.04 for a BSA concentration of $0.01 \mu \mathrm{g} / \mathrm{ml}$ (No. 14), 1.06 for $0.1 \mu \mathrm{g} / \mathrm{ml}$ (No. 15), 1.06 for $1 \mu \mathrm{g} / \mathrm{ml}$ (No. 16), and 1.08 for $10 \mu \mathrm{g} / \mathrm{ml}$ (No. 17). The detection limit of BSA was $0.01 \mu \mathrm{g} / \mathrm{ml}(=10 \mathrm{ng} / \mathrm{ml})$. The plots showed an approximate straight line with a correlation coefficient $\left(R^{2}\right)$ of 0.887 .

\subsection{Evaluation of detection voltage using aminated cellulose film with chemically bound protein}

Figure 12 shows the relative voltage obtained for sensor evaluation of the aminated cellulose film with adsorbed $\mathrm{Na}^{+}$ions as a control (No. $\left.{ }^{*} 18\right)$, aminated cellulose film bound to GA with adsorbed $\mathrm{Na}^{+}$ions (No. ${ }^{*} 19$ ), aminated cellulose film bound to GA and PL with adsorbed $\mathrm{Na}^{+}$ions (No. *20), and aminated cellulose film bound to GA, PL, GA, and BSA with adsorbed $\mathrm{Na}^{+}$ions (No. *21). Preparation details of these samples are summarized in Table 4. $R_{E}$ of the control (No. 18) is 1 . $R_{E}$ of No. 19 showed a marked decrease to 0.8 . This value changed to 0.83 for No. 20. Meanwhile, $R_{E}$ of No. 21 was 0.93 .

The relationship between the relative voltage of the aminated cellulose film chemically bound to BSA with adsorbed $\mathrm{Na}^{+}$ions and the concentration of BSA is presented in Fig. 13. The preparation details of Nos. $* 23$ to $* 26$ are summarized in Table 4. No. 22 was a control comprising aminated cellulose film with adsorbed $\mathrm{Na}^{+}$ions with $R_{E}$ equal to 1 . For Nos. 23 to 26, $R_{E}$ increased with the concentration of BSA, with $R_{E}$ of 0.95 for a BSA concentration of $0.01 \mu \mathrm{g} / \mathrm{ml}$ (No. 23), 0.96 for $0.1 \mu \mathrm{g} / \mathrm{ml}$ (No. 24), 0.99 for $1 \mu \mathrm{g} / \mathrm{ml}$ (No. 25), and 1.03 for $10 \mu \mathrm{g} / \mathrm{ml}$ (No. 26). The detection limit of BSA was $0.01 \mu \mathrm{g} / \mathrm{ml}(=10 \mathrm{ng} / \mathrm{ml})$. A logarithmic plot of BSA concentration against $R_{E}$ gave a straight line with $R^{2}$ of 0.943 .

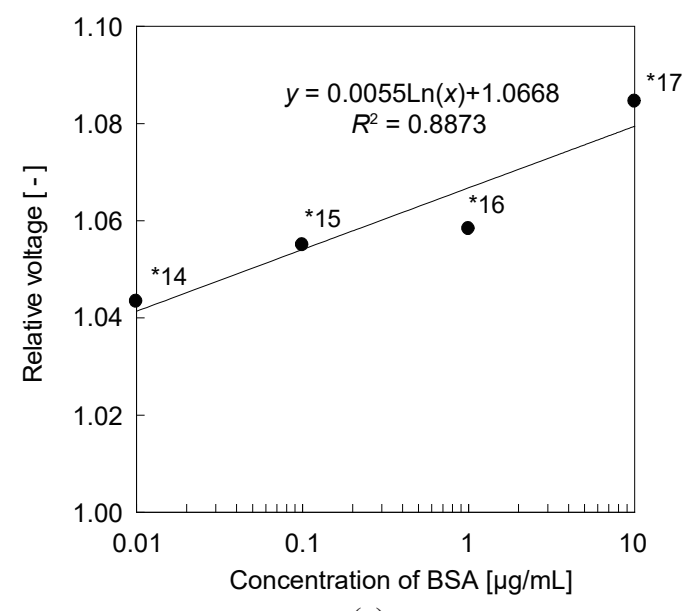

(a)

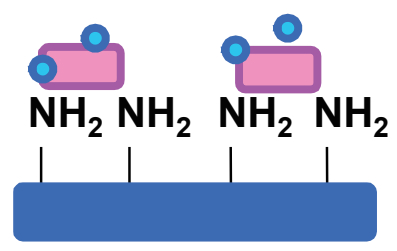

(b)

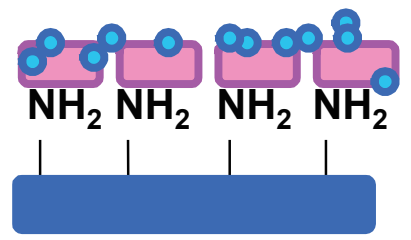

(c)

Fig. 11. (Color online) (a) Relationship between the relative voltage of aminated cellulose with adsorbed BSA with $\mathrm{Na}^{+}$ions and the concentration of BSA. (b) and (c) show different concentrations of BSA and $\mathrm{Na}^{+}$on the cellulose surface. The preparation procedures of $* 14$ to $* 17$ are summarized in Table 4 . BSA is bovine serum albumin. 


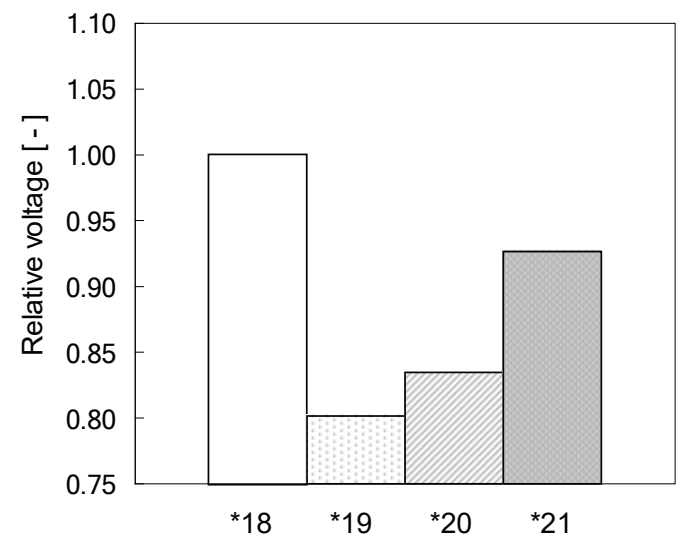

Fig. 12. Relative voltage obtained from sensor evaluation of *18) aminated cellulose with adsorbed $\mathrm{Na}^{+}$ions (control), *19) aminated cellulose bound to GA and with adsorbed $\mathrm{Na}^{+}$ions, *20) aminated cellulose bound to GA and PL with adsorbed $\mathrm{Na}^{+}$ions, and $* 21$ ) aminated cellulose bound to GA, PL, GA, and BSA with adsorbed $\mathrm{Na}^{+}$ ions. The preparation procedures of these samples are summarized in Table 4. BSA is bovine serum albumin, GA is glutaraldehyde, and PL is polylysine.

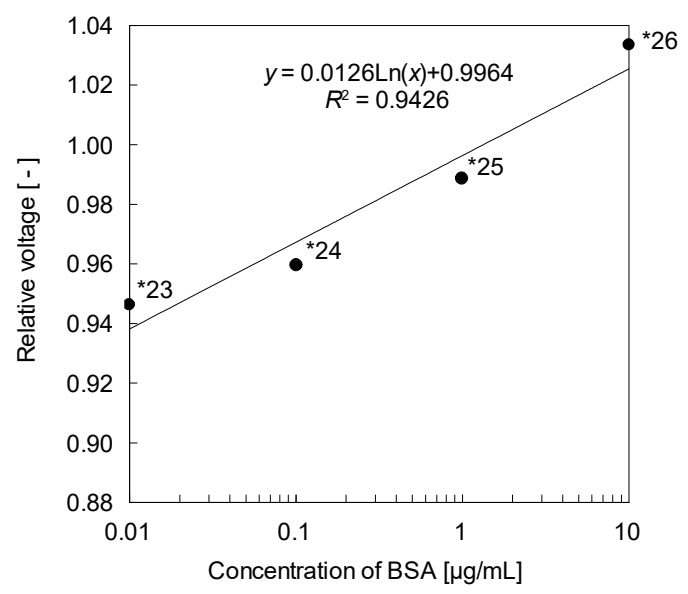

(a)

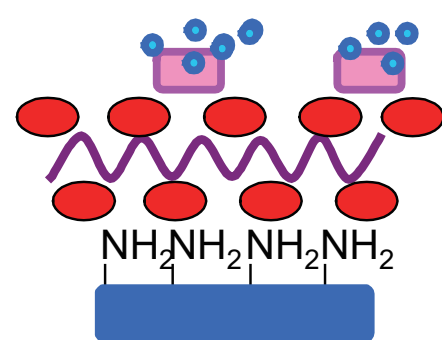

(b)

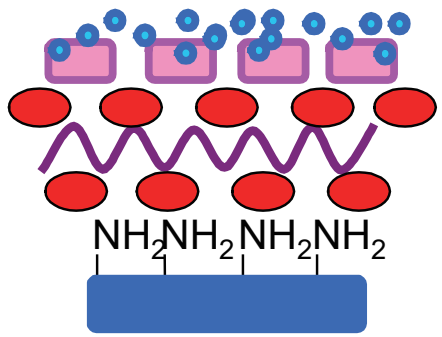

(c)

Fig. 13. (Color online) Relationship between relative voltage of aminated cellulose chemically bound to BSA and $\mathrm{Na}^{+}$ions and the concentration of BSA. The preparation procedures of $* 23$ to $* 26$ are summarized in Table 4 . BSA is bovine serum albumin.

\section{Discussion}

\subsection{Detection voltages of different sensor films}

Cellulose has hydroxyl groups in its molecular structure and its surface exhibits a negative charge in water; ${ }^{(12)}$ therefore, $\mathrm{Na}^{+}$ions readily adsorb on the surface of the cellulose film as counterions. This is the reason for the increase in $R_{E}$ for the cellulose film (No. 2 in Fig. 9) 
compared with that of DW as a control. In contrast, the surface of aminated cellulose film has a positive charge originating from the amino groups. As a result, the adsorption of $\mathrm{Na}^{+}$ions decreases. This is the reason why $R_{E}$ decreased after the amination of the cellulose surface (No. 5 in Fig. 9) compared with that of an unmodified cellulose surface (No. 2 in Fig. 9).

In contrast, $R_{E}$ obtained for a Teflon control (No. 8), as shown in Fig. 9, was almost constant because of its lack of polarity. ${ }^{(13)}$ As inferred from the above results, detection voltage is affected by the charge on the film surface, and the polarity of the surface depends on the film material as well as the surface chemical structure.

\subsection{Detection voltage of aminated cellulose film with adsorbed protein and cations}

Proteins have carboxyl and hydroxyl groups in their molecular structure; hence, their surface is negatively charged in water. ${ }^{(14)}$ Conversely, the surface of an aminated cellulose film has a positive charge originating from the amino groups. As a result, protein is readily adsorbed on surfaces modified with amino groups. We reported that some chelate compounds are strongly adsorbed on the surface of silica particles modified with aminoalkyl groups, causing the sensor detection voltage to change. ${ }^{(15)}$ The interaction between aminated silica surfaces and chelate compounds was also analyzed by quantum chemical calculations, which indicated that amino groups on the surface were interacting strongly with the chelate compound with similar molecular orbital levels. It has also been reported that synthesized DNA is adsorbed on silica particle surfaces modified with aminoalkyl groups, and subsequent conjugation of the adsorbed DNA with a fluorescent compound allowed spectrophotometric analysis. ${ }^{(16)}$ Therefore, protein, DNA, and some chelate compounds can strongly adsorb on solid surfaces modified with amino groups such as aminated silica particles and/or cellulose film.

The present results suggest that adsorbed BSA increases the negative charge on the cellulose film because of its hydroxyl and/or carboxyl groups. This is the reason why the $R_{E}$ of aminated cellulose with adsorbed BSA (No. 11; see Fig. 10) was larger than that of the control unmodified cellulose (No. 10 in Fig. 10). Furthermore, it suggests that a negatively charged surface suffered upon the adsorption of BSA and the electrostatic adsorption of $\mathrm{Na}^{+}$as a counterion. This is why the $R_{E}$ of aminated cellulose with adsorbed BSA and $\mathrm{Na}^{+}$ions (No. 12 in Fig. 10) was larger than that of aminated cellulose with only adsorbed BSA (No. 11 in Fig. 10). This study revealed that the sensitivity of detection of the EC sensor using the aminated cellulose film with adsorbed protein was increased by the addition of $\mathrm{Na}^{+}$counterions.

\subsection{Detection of protein using aminated cellulose film modified with polypeptide}

GA is composed of an ethylene chain as a backbone with aldehyde groups at both ends that can react with amino groups to form a chemical bond. As a result, GA is widely used as a crosslinker to connect amino groups. ${ }^{(17)}$ According to the results shown in Fig. 12, GA reacted with amino groups on the surface of the aminated cellulose film to form an ethylated surface (No. 19). Ethyl groups, like hydrocarbons, act as insulators. Therefore, the EC of the aminated cellulose film with bound GA decreased compared with that of the aminated cellulose film.

PL is composed of several thousand lysine amino acid monomers to form a straight polymer. The side chains of PL consist of lysine residues or amino groups. ${ }^{(18)}$ The results for No. 20 in Fig. 12 reveal that PL linked to amino groups on the surface of the aminated cellulose film through GA, 
causing the surface to be further aminated and exhibit positive charge. The EC of the aminated cellulose film with bound PL and GA (No. 20) was slightly higher than that of the aminated cellulose with bound GA alone (No. 19 in Fig. 12).

This study further confirmed that BSA could chemically bind with PL through GA, and the resulting modified film (No. 21 in Fig. 12) clearly showed a different $R_{E}$ than that of No. 20. This suggests that $\mathrm{Na}^{+}$as a counterion was adsorbed on the aminated cellulose film modified with BSA, which further increased surface charge. The above results indicate that the EC sensor system was able to detect changes in the surface charge of the cellulose-based films caused by the chemical bonding of protein.

In Figs. 11(b) and 11(c), models of physically adsorbed protein on aminated cellulose films with small and large amounts of adsorbed protein, respectively, are shown. In the case of a small amount of adsorbed protein, the amount of adsorbed $\mathrm{Na}^{+}$ions is also small [Fig. 11(b)]. The amount of adsorbed $\mathrm{Na}^{+}$ions increases with the amount of protein [Fig. 11(c)]. The EC changes in a well depend on the amount of adsorbed counterions and thus the content of protein adsorbed on the aminated cellulose film.

In Figs 13(b) and 13(c) show a schematic model of the aminated cellulose film with chemically bound protein through linkage with a polypeptide as a binder. The PL binder has an amino residue as a side chain and overall positive charge. Therefore, the adsorption of $\mathrm{Na}^{+}$ions is hindered by the positively charged binder layer. This suggests that $\mathrm{Na}^{+}$ions are less likely to be adsorbed than when PL is present, as in Fig. 13(b), and/or larger [Fig. 13(c)]. EC changes in a well depending on the amount of adsorbed counterions for a protein-bound aminated cellulose film through a polypeptide binder. Thus, in this study, we clarify that the EC of an aminated cellulose film increases with the content of protein whether it is physically absorbed on the surface (Fig. 11) or chemically bound through a binder substance (Fig. 13).

According to the results of the chemical binding method shown in Fig. 13, the detected EC is almost the same as the theoretical value. This suggests that the surface modification of the aminated cellulose film by chemical binding is better than physical adsorption for achieving reproducible measurements using sensor films in our EC sensor screening system.

\section{Conclusions}

We developed a wireless EC sensor screening system that achieved parallel detection of five EC signals from electrode pairs in wells containing $5 \mu \mathrm{l}$ samples in $10 \mathrm{~s}(N=5)$. We also developed sensor films that responded to physical adsorption and/or chemical bonding of protein with $\mathrm{Na}^{+}$as a counterion by changes in EC. A mechanism for the increase in the sensitivity of the sensor films with immobilized protein in the presence of a counterion was proposed. The EC for the aminated cellulose film with physically adsorbed BSA and $\mathrm{Na}^{+}$increased linearly with BSA concentration, with $R^{2}$ of 0.87 . The EC of the aminated cellulose film with protein chemically bound through PL with GA as a binder layer depended on the BSA concentration, with an $R^{2}$ of 0.943 . The detection limit of BSA was $10 \mathrm{ng} / \mathrm{ml}$ for both types of sensor. Overall, our results suggest that the surface modification of an aminated cellulose film by chemical binding is better than physical adsorption for achieving reproducible measurements for sensor films using the EC sensor screening system. 


\section{Acknowledgements}

This work was supported by the Japan Society for the Promotion of Science under a Grantin-Aid for Scientific Research [Scientific Research (C): 23560409]. We acknowledge the late Hikaru Sato, from AR'S Co., Ltd., Japan, for his assistance with the production of the wireless sensor screening system. We also thank Aluvac Coating Co., Ltd., Japan for the production of the sensor array chip Well sensor-3, and Shin-Etsu Chemical Co., Ltd., Japan for providing the silane compound KBM-603.

\section{References}

1 J. A. Grant, R. M. Goldblum, R. Rahr, D. O. Thueson, J. Farnam, and J. Gillaspy: J. Allergy Clin. Immunol. 68 (1981) 112

2 J. G. Lewis and P. A. Elder: J. Steroid Biochem. 22 (1985) 673.

3 H. J. Holtke and C. Kessler: Nucleic Acids Res. 18 (1990) 5843.

4 L. Sartore, M. Barbaglio, L. Borgese, and E. Bontempi: Sens. Actuators, B 155 (2011) 538.

5 M. Mrksich, G. B. Sigal, and G. M. Whitesides: Langmuir 11 (1995) 4383.

6 R. Kurita, Y. Hirata, S. Yabuki, Y. Yokota, D. Kato, Y. Sato, F. Mizutani, and O. Niwa: Sens. Actuators, B 130 (2008) 320.

7 M. Somasundrum and J. V. Bannister: Sens. Actuators, B 15 (1993) 203.

8 T. Isoda, I. Urushibara, M. Sato, H. Uemura, H. Sato, and N. Yamauchi: Sens. Actuators, B 129 (2008) 958.

9 T. Isoda, H. Sato, I. Urushibara, S. Uchida, K. Kusuyama, T. Kojima, T. Asaka, and I. Nitta: Sens. Mater. 23 (2011) 237.

10 J. P. Hansen: Ann. Rev. Phys. Chem. 51 (2000) 209.

11 R. Tamamusi and K. Takahashi: Essential Electrochemistry (Tokyo-Kagakudojin, Tokyo, 2000) pp. 111-135.

12 V. Ribitsch, K. Stana-Kleinschek, and S. Jeler: Colloid. Polym. Sci. 274 (1996) 388.

13 J. J. Chessick, F. H. Healey, and A. C. Zettlemoyer: J. Phy. Chem. 60 (1956) 1345.

14 S. Fukuzaki, H. Urano, and K. Nagata: J. Ferm. and Bioeng. 81 (1996) 163.

15 T. Isoda, I. Urushibara, H. Sato, and N. Yamauchi: Sensors 12 (2012) 8405.

16 T. Isoda and R. Maeda: J. Funct. Biomater. 3 (2012) 601.

17 A. Webster, M. D. Halling, and D. M. Grant: Carbohydrate Res. 342 (2007) 1189.

18 E. Wernersson, J. Heyda, A. Kubíčková, T. Křížek, P. Coufal, and P. Jungwirth: J. Phys. Chem. B 114 (2010) 11934. 